\title{
Laser in situ keratomileusis in patients with collagen vascular disease: a review of the literature
}

This article was published in the following Dove Press journal:

Clinical Ophthalmology

2 November 2012

Number of times this article has been viewed

\author{
Rachel G Simpson' \\ Majid Moshirfar ${ }^{2}$ \\ Jason N Edmonds ${ }^{2}$ \\ Steven M Christiansen ${ }^{2}$ \\ Nicholas Behunin ${ }^{2}$ \\ 'The University of Arizona College \\ of Medicine, Phoenix, AZ, USA; \\ ${ }^{2}$ John A Moran Eye Center, \\ The University of Utah School of \\ Medicine, Salt Lake City, UT, USA
}

\begin{abstract}
Purpose: To evaluate the current United States Food and Drug Administration (FDA) recommendations regarding laser in situ keratomileusis (LASIK) surgery in patients with collagen vascular diseases (CVD) and assess whether these patients make appropriate candidates for laser vision correction, and offer treatment recommendations based on identified clinical data.

Methods: A literature search was conducted using PubMed, Medline, and Ovid to identify all existing studies of LASIK in patients with collagen vascular diseases. The search was conducted without date limitations. Keywords used for the search included MeSH terms: laser in situ keratomileusis, LASIK, refractive surgery, ocular surgery, and cataract surgery connected by "and" with the following MeSH and natural-language terms: collagen vascular disease, rheumatic disease, systemic disease, rheumatoid arthritis, systemic lupus erythematosus, Sjögren's syndrome, seronegative spondyloarthropathy, HLA B27, ankylosing spondylitis, reactive arthritis, psoriatic arthritis. The abstracts for all studies meeting initial search criteria were reviewed; relevant studies were included. No prospective studies were found; however, four retrospective case studies were identified that examined LASIK surgery in patients with CVD. Several case reports were also identified in similar fashion.

Results: The FDA considers CVD a relative contraindication to LASIK surgery, due largely to the ocular complications associated with disease in the CVD spectrum. However, recent studies of LASIK in patients with CVD indicate LASIK may be safe for patients with very well-controlled systemic disease, minimal ocular manifestations, and no clinical signs or history of dry-eye symptoms.

Conclusion: LASIK surgery may be safe in patients with rheumatoid arthritis or systemic lupus erythematosus and the seronegative spondyloarthropathies if stringent preoperative criteria are met. Evidence suggests patients with Sjögren's syndrome are not suitable candidates for LASIK.
\end{abstract}

Keywords: refractive surgery, ocular surgery, rheumatoid arthritis, systemic lupus erythematosus, Sjögren's syndrome, seronegative spondyloarthropathies

\section{Introduction}

The United States Food and Drug Administration (FDA) initially approved photorefractive keratectomy (PRK) for laser vision correction in the early 1990s. At that time, the FDA established a list of ocular and systemic contraindications to refractive surgery. Included among the systemic relative contraindications was the subset of autoimmune inflammatory disorders known as collagen vascular diseases (CVD). The major diseases in this group traditionally include rheumatoid arthritis (RA), systemic lupus erythematosus (SLE), Sjögren's syndrome (SS), and the seronegative
Correspondence: Majid Moshirfar John A Moran Eye Center,

The University of Utah School of Medicine, 65 Mario Capecchi Drive, Salt Lake City, UT 84I32, USA

$\mathrm{Tel}+\mid$ 80I $58 \mid 2352$

Fax + I 80| 58| 3357

Email majid.moshirfar@hsc.utah.edu submit your manuscript | www.dovepress.com

Dovepress

http://dx.doi.org// 0.2147/OPTH.S36690 which permits unrestricted noncommercial use, provided the original work is properly cited. 
spondyloarthropathies (SpA; ankylosing spondylitis, reactive arthritis, and psoriatic arthritis). All of these diseases have well-documented eye manifestations (Table 1).

When this recommendation was issued, there were little data available on the safety and efficacy of refractive surgery in patients with CVD, as laser vision correction was a relatively new field at the time. Therefore, the FDA used the known ocular complications of these conditions and documented outcomes of nonlaser ocular surgery to justify their recommendation. ${ }^{1}$ They expressed a number of concerns, including the possibilities that surgical intervention might worsen ocular disease and ultimately result in compromised refractive outcomes, and that the abnormal inflammatory response in these patients could result in significant corneal complications, including scarring, ulceration, and melting. ${ }^{2}$ When the FDA approved laser in situ keratomileusis (LASIK) several years later, the same recommendations were applied. ${ }^{3}$ In 2002, the American Academy of Ophthalmology (AAO) and the American Society of Cataract and Refractive Surgeons both echoed the FDA's recommendations with respect to patients with CVD. ${ }^{1,2}$

Recently, several studies have attempted to clarify precisely which collagen vascular diseases, if any, predispose the patient to a higher risk of complications

Table I Frequency and nature of ocular manifestations in collagen vascular diseases

\begin{tabular}{|c|c|c|}
\hline Disease & $\begin{array}{l}\text { Ocular } \\
\text { manifestations }\end{array}$ & $\begin{array}{l}\text { Percent of patients } \\
\text { with ocular symptoms }\end{array}$ \\
\hline \multirow[t]{6}{*}{$\begin{array}{l}\text { Rheumatoid } \\
\text { arthritis }\end{array}$} & $\begin{array}{l}\text { Keratoconjunctivitis } \\
\text { sicca }\end{array}$ & $25 \%-30 \%$ \\
\hline & Scleritis & $5 \%-10 \%$ \\
\hline & Episcleritis & $5 \%-10 \%$ \\
\hline & Ulcerative/ & $3 \%-5 \%$ overall \\
\hline & necrotizing keralilis & $30 \%-70 \%$ in patients \\
\hline & & with scleritis/episcleritis \\
\hline \multirow[t]{5}{*}{$\begin{array}{l}\text { Systemic lupus } \\
\text { erythematos }\end{array}$} & $\begin{array}{l}\text { Keratoconjunctivitis } \\
\text { sicca }\end{array}$ & $15 \%-20 \%$ \\
\hline & Scleritis & $1 \%-2 \%$ \\
\hline & Episcleritis & $1 \%-2 \%$ \\
\hline & Keratitis & Rare \\
\hline & Retinal vasculitis & $\begin{array}{l}2 \%-3 \% \text { in well controlled } \\
\text { patients } 28 \% \text { in active or } \\
\text { aggressive disease }\end{array}$ \\
\hline $\begin{array}{l}\text { Sjögren's } \\
\text { syndrome }\end{array}$ & $\begin{array}{l}\text { Keratoconjunctivitis } \\
\text { sicca }\end{array}$ & $100 \%$ \\
\hline $\begin{array}{l}\text { Ankylosing } \\
\text { spondylitis }\end{array}$ & Uveitis & $30 \%-33 \%$ \\
\hline Psoriatic & Conjunctivitis & $30 \%-65 \%$ \\
\hline arthritis & Uveitis & $20 \%$ \\
\hline Reactive & Conjunctivitis & $30 \%-65 \%$ \\
\hline arthritis & Uveitis & $35 \%-40 \%$ \\
\hline
\end{tabular}

and adverse events, and whether some patients may be acceptable candidates for LASIK. This review examines the current FDA recommendations against LASIK surgery in patients with CVD by reviewing the ocular complications of CVD and examining the current literature on the outcomes of LASIK and other ocular surgeries in this patient population; based on these findings, we offer recommendations for the refractive surgeon considering LASIK surgery in these patients.

\section{Ocular involvement in collagen vascular disease Sjögren's syndrome}

$\mathrm{SS}$ is an autoimmune inflammatory disease of the salivary and lacrimal glands, manifested clinically as keratoconjunctivitis sicca (KCS, or dry eye) (Figure 1) and xerostomia (dry mouth). The diagnosis of SS is based on clinical signs and symptoms (dry eye and dry mouth) and either a positive salivary gland biopsy showing inflammatory changes or positive anti-Ro or anti-La serum antibodies. There are two forms of SS. Primary SS occurs in patients without comorbid inflammatory or autoimmune conditions and is relatively rare (incidence 3.9/100,000). ${ }^{4}$ Secondary SS is diagnosed when the symptoms of SS complicate other inflammatory conditions, such as RA, SLE, and scleroderma. Secondary $\mathrm{SS}$ is significantly more common than primary. ${ }^{5}$

The etiology of the KCS symptoms seen in SS is lacrimal gland hypofunction and tissue destruction, and is thought to be the result of two separate autoimmune processes. ${ }^{6,7}$ In healthy lacrimal glands, efferent neurons controlled by the autonomic nervous system innervate the lacrimal glands and fire on muscarinic $\left(\mathrm{M}_{3}\right)$ receptors to stimulate tear secretion. ${ }^{8}$ In $\mathrm{SS}$, autoantibodies to the $\mathrm{M}_{3}$ receptor block signals from the central nervous system to lacrimal glands, resulting in

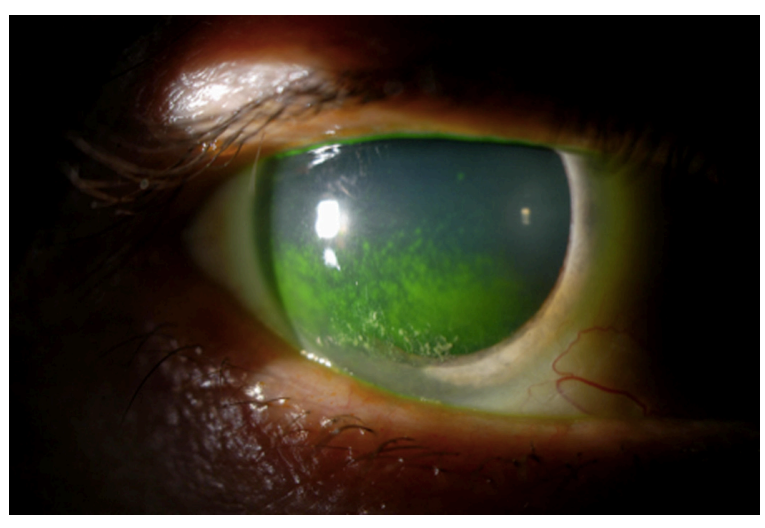

Figure I keratoconjunctivitis sicca in a patient with primary Sjögren's syndrome. 
hyposecretion of tears. ${ }^{9}$ Concurrent destruction of lacrimal gland tissue appears to be the result of $\mathrm{CD}^{+} \mathrm{T}$ lymphocytemediated release of granzyme A, perforin, and proinflammatory cytokines, which induce apoptosis in lacrimal gland cells. ${ }^{10}$ The end result is both gland dysfunction and tissue destruction.

Symptoms of KCS are the result of reduced tear production and include dryness, discomfort, irritation, burning, foreignbody sensation, and photophobia. Chronically dry corneal epithelial tissue is rapidly devitalized and sloughs off easily during blinking or eye rubbing, which can lead to epithelial erosions and superficial punctate keratopathy. These disruptions to corneal epithelial integrity predispose the eye to bacterial keratitis and increase the risk for ocular infections. ${ }^{11}$

\section{Rheumatoid arthritis}

RA is a chronic, autoimmune disease affecting the small joints of the peripheral skeleton that frequently involves numerous nonarticular organ systems, including the eye. It is the most common condition in the collagen vascular spectrum, with an annual incidence of 40/100,000.${ }^{12}$ Patients with RA are classified into three categories based on the number of joints affected, serum markers, and the presence or extent of extra-articular symptoms (Table 2).

Twenty-five percent of RA patients have comorbid SS, making KCS the most common eye complaint in RA patients. It should be noted that for the purposes of categorizing RA disease severity, comorbid SS is not considered an extra-articular symptom, thus patients with secondary SS can still have mild or moderate RA. ${ }^{13}$ Episcleritis and scleritis affect 5\%-10\% of RA patients, and the presence of either condition signifies severe disease. ${ }^{14}$ Rheumatoid arthritis is the most common cause of scleritis, and $33 \%$ of scleritis patients presenting to the ophthalmology clinic have underlying RA. ${ }^{15,16}$ In patients with RA-related scleritis or episcleritis, acute keratitis complicates $30 \%-70 \%$ of cases. The keratitis associated with necrotizing scleritis characteristically seen in RA patients is marked by an inflammatory cell infiltrate that often results in corneal scarring, ulceration, or melting (Figure 2). ${ }^{14,16}$

The pathophysiology of KCS in RA is identical to that for SS, and it is likely RA shares a common immunologic pathway with SS. ${ }^{17}$ The pathophysiology of the characteristic scleritis seen in RA patients is believed to be due to immunecomplex deposition within the scleral vessels, causing fibrinoid necrosis and thrombotic occlusion of blood vessels, resulting in a significant inflammatory response in the sclera and producing the characteristic pain and inflammation. ${ }^{18}$
Table 2 Classification of rheumatoid arthritis

\section{Classification of rheumatoid arthritis ${ }^{\mathrm{a}}$}

(Minimum diagnostic criteria $=$ sinovitis and $6+$ points)

I. Number of sites involved

2-10 large joints

I-3 small joints

4-10 small joints

Greater than 10 joints

2. Serology (CCP or RF)

Low positive values (above ULN)

High positive values ( 3 times ULN)

3. Acute phase inflammatory markers

ESR or CRP and above ULN

4. Symptom duration

At least 6 weeks

2

3

Disease classification

Mild disease

Diagnostic criteria (above) satisfied

Less than 6 joints involved

No evidence of joint erosion on radiograph

No extraarticular disease

Moderate disease

6-20 affected joints

No extraarticular symptoms

Some combination of features below

CRP/ESR elevation

Positive RF and/or anti-CCP antibodies

Mild joint erosion on radiograph

Severe disease

$20+$ joints affected

Elevation of CRP/ESR

One or more of the following:

Extraarticular symptoms

High titers of RF/anti-CCP

Anemia of chronic disease or hypoalbuminemia

Significant joint deformities on physical exam

Radiographs showing bony erosions

Note: a2010 ACR/EULAR criteria available at: http://www.rheumatology.org/ practice/clinical/classification/ra/ra_20I0.asp.

Abbreviations: CCP, anti-cyclic citrullinated protein antibodies; RF, rheumatoid factor; ULN, upper limit of normal; CRP, C-reactive protein; ESR, erythrocyte sedimentation rate; ACR, American College of Rheumatology; EULAR, European League Against Rheumatism.

\section{Systemic lupus erythematosus}

SLE is an inflammatory autoimmune disease affecting multiple organ systems. Incidence varies according to race and sex; African-American females have the highest reported incidence at $406 / 100,000$, but overall incidence is much lower, at $1-25 / 100,000 .{ }^{19}$ There is a wide variety of ocular complications associated with SLE. Approximately $25 \%$ of SLE patients have comorbid secondary SS, making KCS the most common eye complaint in lupus patients. ${ }^{20-22}$ Patients with discoid SLE are prone to develop persistent lower-eyelid lesions, a risk factor for eye infection. ${ }^{22}$ Lupus retinitis occurs in $10 \%$ of patients, manifesting as cotton-wool spots, hard exudates, and intraretinal hemorrhages. ${ }^{23,24}$ Persistent ocular complications or retinitis are markers for aggressive or poorly 


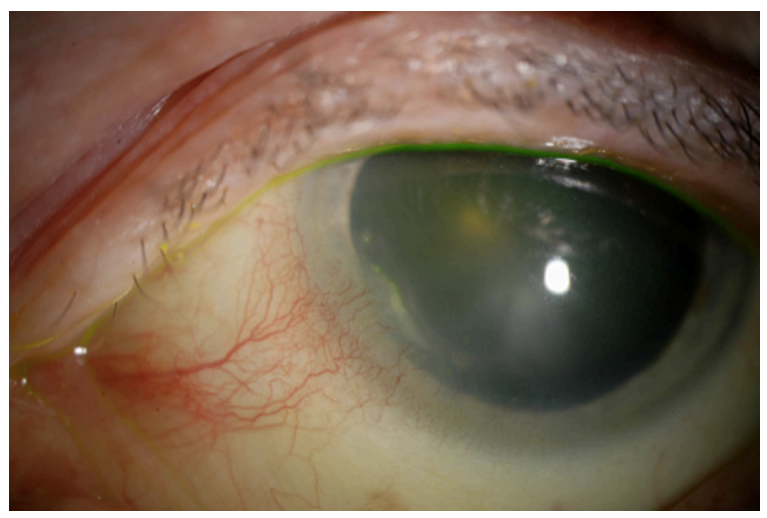

Figure 2 Peripheral ulcerative keratitis in a patient with rheumatoid arthritis.

controlled disease; $29 \%$ of hospitalized SLE patients have retinal manifestations compared to only $3 \%$ of SLE patients in ambulatory settings. ${ }^{25-29}$

The pathophysiology of SLE is attributed to a deranged immune system and the production of several different autoantibodies. ${ }^{30}$ The cross-reaction between autoantibodies and their antigens produces immune complexes, which develop in the microvasculature and activate the complement system, leading to global inflammation and tissue destruction. The immune complexes themselves deposit in basement membranes throughout the body (eye, kidney, skin, among others), where they disrupt the integrity of the membrane. Immune-complex deposition has been confirmed in blood vessels and basement membranes of the cornea. ${ }^{31}$ The corneal complications of SLE are likely the result of immune complex-mediated disruption of basement membrane tissue, compounded by the proinflammatory effects of a chronically activated complement system. This is further compounded in patients with comorbid secondary SS. ${ }^{32}$

\section{Seronegative spondyloarthropathies}

$\mathrm{SpA}$ is a group of inflammatory autoimmune diseases that commonly affect the spine and peripheral joints, and are all associated with human leukocyte antigen (HLA) B27 and negative rheumatoid factor (RF). This group of diseases traditionally includes psoriatic arthritis, ankylosing spondylitis, and reactive arthritis (formerly Reiter's syndrome). Incidence of reported symptomatic disease is low, approximately $1-10 / 100,000$ for each disease, though it appears that between $8 \%$ and $10 \%$ of individuals are positive for the HLA-B27 allele and are unaware of their carrier status. ${ }^{33-36}$ The primary ocular complications of these conditions are acute anterior uveitis, iritis, and conjunctivitis. Anterior uveitis presents with acute onset of eye redness and pain, intense photophobia, blepharospasm, and myosis. ${ }^{35}$
Complications from uveitis include band keratopathy, posterior synechiae, and cataracts. Overall, $30 \%-40 \%$ of patients with SpA will experience an acute attack of anterior uveitis at some point during the disease course. Notably, the risk of recurrent uveitis is fairly low, with some studies reporting a recurrence rate as low as $2.6 \% .^{35,37,38}$ Unlike the previous collagen vascular conditions, comorbid SS is rare in these patients.

The pathophysiology of the ocular complications associated with SpA is complex and poorly understood. What is known is that activated $\mathrm{T}$ lymphocytes reactive to autoantigens in the eye infiltrate the ocular tissue and release proinflammatory mediators. ${ }^{39}$

\section{Ocular surgery in collagen vascular disease}

Two retrospective studies of reasonable size have reported minimal complications in RA patients after cataract extraction. In a retrospective study of cataract surgery in RA patients, Matsuo et al reported complications in four of 33 eyes (12\%) after cataract surgery. They also found roughly half of the patients experienced extended postoperative inflammation and elevated serum RF, but this was not associated with any visual complications and resolved by 6 months postoperatively. ${ }^{40}$ Jones and Maguire reported three complications in 86 eyes $(3.5 \%)$ of RA patients following cataract surgery. The three patients all developed diffuse superficial punctate keratopathy, which resolved without permanent sequelae. All three patients had a documented history of KCS. ${ }^{41}$ Fox et al reported good outcomes and no complications in a series of 16 patients with uveitis secondary to ankylosing spondylitis who underwent cataract extraction. ${ }^{42}$

There are several reports of postsurgical corneal ulcerations in CVD patients, although in all cases patients had either significant KCS symptoms or active systemic disease. Maffett et al published a case series of eight patients with RA or SLE, wherein six developed corneal ulcerations after cataract surgery. All six patients had comorbid secondary SS. ${ }^{43}$ A case of severe corneal melting after PRK in a patient with an active lupus flare was reported by Sieler and Wollensak. ${ }^{44}$ Shannon et al described corneal melting after Descemet's stripping endothelial keratoplasty in two patients with previously undiagnosed primary SS. In both cases, the surgeon observed significant dry eye intraoperatively. While neither patient had previously been diagnosed with SS or dry eye, a thorough postoperative history and review of systems revealed each patient had suffered from chronic dry mouth and dry eye for years. ${ }^{45} \mathrm{Ou}$ and Manche also described a 
case of sterile corneal melting in a patient with undiagnosed $\mathrm{SS}$, this time occurring after conductive keratoplasty. This patient also had a history of KCS symptoms, but had never been evaluated for SS. ${ }^{46}$ Other reported complications in these patients include a case of peripheral ulcerative keratitis after trabeculectomy in a patient with RA and a history of KCS, and one case report of necrotizing scleritis, also in an RA patient with secondary SS. ${ }^{47,48}$

\section{LASIK surgery in collagen vascular disease}

For years, the only data supporting or refuting the FDA and AAO recommendations regarding LASIK in patients with CVD were a small assortment of case reports. Recently, several larger, retrospective studies have examined postLASIK complications and refractive outcomes in these patients. These studies have started to reveal a better understanding of the outcomes and risks of laser vision correction in this patient population.

In the first study to examine LASIK outcomes in CVD patients, Alió et al described good refractive outcomes and a very low rate of complications. This retrospective, observational clinical study of 44 eyes with "rheumatic diseases" represented a broad selection of diseases in the CVD spectrum: nine eyes with RA, five eyes with SLE, six eyes with ankylosing spondylitis, and eight with psoriatic arthritis were included. The preoperative selection criteria were stringent. Acceptable candidates had no evidence of any active ocular pathology or inflammation and a confirmed 6-month ocular symptom-free period prior to surgery. Patients were required to have stable systemic disease, as confirmed by a rheumatologist, with no history of symptom flare within 6 months. Patients on multidrug regimens for disease control were excluded. Finally, the patients needed to exhibit normal tear function on exam, confirmed by a normal tear breakup time (TBUT) test, and a history negative for secondary SS or KCS. Postoperative refractive outcomes were good, with over $90 \%$ of the patients demonstrating an uncorrected visual acuity (UCVA) of 20/25 or better at 6 months postoperatively. At the time of last follow-up, no eyes had experienced abnormal scarring, interface reactions, epithelial ingrowth, diffuse lamellar keratitis, corneal ulceration, or melting. Four eyes developed symptomatic dry eye requiring lubricating drops that had not resolved by 6 months postoperatively. ${ }^{49}$

After Alió demonstrated good outcomes in this patient population, Cobo-Soriano et al were able to replicate the outcomes in an even larger group of patients. The inclusion criteria were identical to that of Alió. The study included 31 SLE eyes, 29 RA eyes, and two eyes from patients with ankylosing spondylitis. Refractive outcomes were comparable to those seen by Alió. No serious complications were reported; however, mild or moderate superficial punctate keratopathy was seen in $15 \%$ of patients. All cases resolved within 6 months. There were no clinically significant cases of postoperative dry eye. ${ }^{1}$

A retrospective case series by Smith and Maloney, with similar inclusion criteria to the studies by Alió and Cobo-Soriano, reported good refractive outcomes and no postoperative complications. This study examined 49 eyes of patients with a wide variety of autoimmune diseases; of these, 19 eyes were from patients with a type of CVD $(\mathrm{SLE}=13, \mathrm{RA}=11, \mathrm{SpA}=10, \mathrm{SS}=2)$. There were no reports of corneal thinning or melting, persistent epithelial defects, keratopathy, scleral thinning, or scleritis in any of the 49 eyes, and the overall complication rate was $0 \%(95 \%$ confidence interval, $0 \%-11.5 \%)^{2}$

A retrospective case-control study by Moshirfar et al looked specifically at patients with positive HLA-B27 status to determine if they experienced a higher incidence of uveitis after LASIK than patients with the HLA-B27 mutation that did not have surgery. The study followed 46 eyes from HLA-B27 positive patients, all of whom were uveitis-free for at least 1 year before the study. From this population, 20 eyes received LASIK surgery, and 26 eyes, representing the control population, did not. Patients who received LASIK were extensively evaluated and preoperatively cleared for surgery by a rheumatologist, uveitis specialist, or both. In the LASIK group, 14 of 20 eyes experienced a total of 20 episodes of postoperative uveitis, an incidence of 0.200 per eye-year. The HLA-B27-positive eyes that did not have surgery experienced a similar incidence of uveitis when compared to the LASIK group; 22 of 26 eyes experienced a total of 32 episodes per eye, an incidence of 0.246 per eye-year. The odds of developing uveitis after LASIK versus that of developing uveitis without LASIK was not statistically significant (odds ratio, $0.42 ; 95 \%$ confidence interval, 0.13-1.39). Further, the post-LASIK episodes of uveitis occurred a mean of 13 months (range 8-18 months) after surgery, and no eye experienced uveitis in the initial 30 days after surgery. The researchers hypothesized that this finding indicated surgery was not the precipitating factor in these patients' uveitis flares. ${ }^{50}$

Several case reports describe poor results after LASIK in patients with CVD. $\mathrm{Li}$ and $\mathrm{Li}$ reported twelve cases of sterile corneal melting after LASIK; of these, five cases 
occurred in patients with CVD $(\mathrm{SLE}=2$, primary $\mathrm{SS}=2$, $\mathrm{RA}=1)$. The preoperative condition of these patients was not disclosed, so the extent of systemic and ocular disease at the time of surgery is unknown. The researchers believed that the corneal melting occurred secondary to poorly managed postoperative epithelial ingrowth. This makes the study difficult to interpret, as it is impossible to determine the underlying etiology for the corneal melting. ${ }^{51}$ As Smith and Maloney suggest, perhaps what is to be learned from this study is that epithelial ingrowth should be aggressively managed if it occurs in patients with CVD. ${ }^{2}$

Lahners et al presented a case of peripheral keratitis after LASIK in an RA patient whose eye showed evidence of recent inflammation. ${ }^{52}$ Liang et al reported two cases of severe dry eye after LASIK in patients with previously well-controlled SS. ${ }^{53}$ Finally, Diaz-Valle reported a case of delayed onset of diffuse lamellar keratitis in a patient with ankylosing spondylitis 3 years post-LASIK. ${ }^{54}$

\section{Recommendations Rheumatoid arthritis}

The four retrospective studies noted above included 49 eyes of patients with RA, and did not report significant adverse refractive outcomes or complications compromising visual acuity in these eyes. Additionally, patients with RA generally have good outcomes following other kinds of eye surgery. Although peripheral keratitis, corneal ulcerations, and necrotizing scleritis have all been reported as postoperative complications in RA patients after eye surgery, these reports all involved a patient with a significant history of dry eye, secondary SS, recent ocular inflammation, or active systemic disease. Further, many RA patients do not experience any ocular complications as a result of their condition. In the $30 \%$ that do, the most common etiology is comorbid SS. While scleritis and episcleritis are also common complications, they occur far less frequently, and occur only in patients with severe disease. Considering the evidence on ocular and LASIK surgery in these patients, and knowing the ocular complications associated with the disease, we conclude LASIK surgery is safe in RA patients with mild disease and no history of dry eye or secondary SS.

\section{Preoperative evaluation}

The preoperative assessment is critical to rule out unacceptable surgical candidates. The first step is to assess and categorize the primary disease as mild, moderate, or severe (Table 2). Current disease activity can then be assessed using the criteria outlined in Table $3 .{ }^{55-58}$
Table 3 Preoperative RA rheumatology evaluation

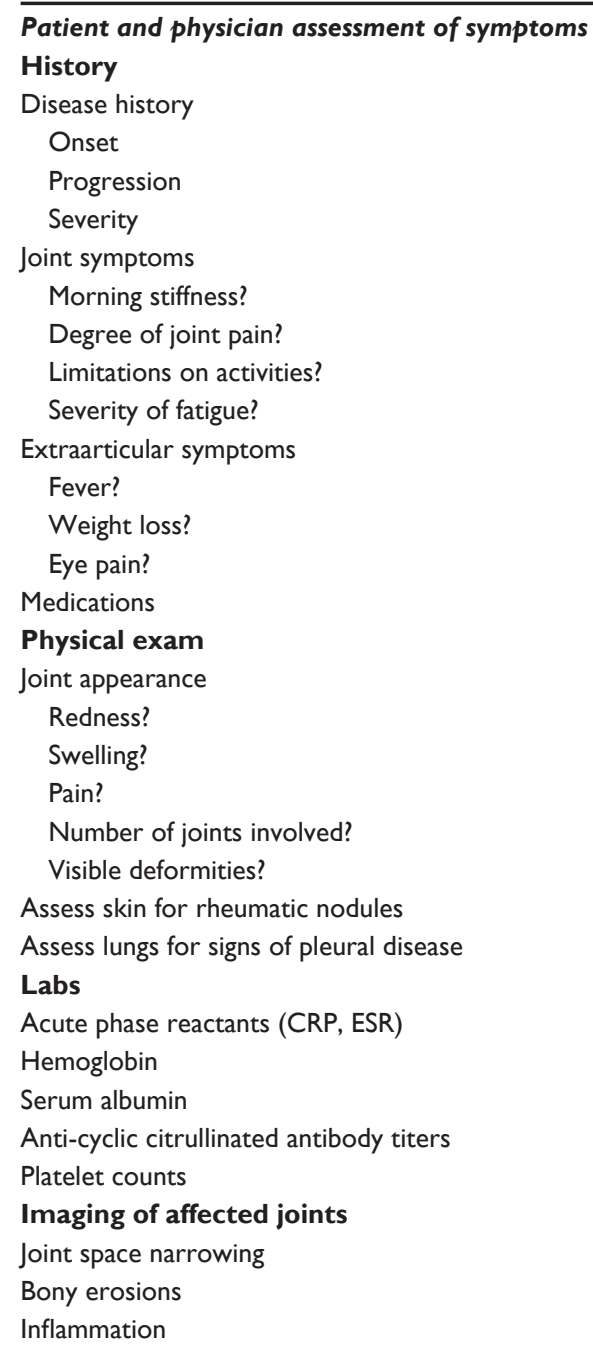

Abbreviations: CRP, C-reactive protein; ESR, erythrocyte sedimentation rate; RA, rheumatoid arthritis.

Patients with findings consistent with moderate or severe disease should immediately be excluded from consideration. We recommend patients also have a document history of a negative SS workup (Table 4). We recommend the patient's rheumatologist conduct the entire rheumatic evaluation. We further recommend that the patient have at least 6 months without any disease flare.

The patient's drug regimen should then be assessed. Patients on long-term multidrug regimens tend to have poor disease control and frequent flares, and should be excluded. Patients who are on low or moderate doses of methotrexate may still be considered for surgery if they meet all other inclusion criteria. Patients on methotrexate should continue their medication at the normal dose during the perioperative period. Evidence from general and orthopedic surgery patients indicates patients on methotrexate who continue their medication throughout the perioperative period 
Table 4 Sjögren's syndrome work-up

\section{Ocular signs}

Sensation of sand or gravel in the eyes?

Daily, persistent, troublesome dry eyes for more than 3 months?

Use eye drops more than 3 times daily?

\section{Ocular tests}

Schimner's test without anesthesia $\leq 5 \mathrm{~mm}$ in $5 \mathrm{~min}$

Rose bengal score $\geq 4$ according to van Bijsterveld's scoring

Oral signs

Daily feeling of dry mouth for more than 3 months?

Recurrent or persistently swollen salivary glands as an adult?

Frequently drink liquids to aid in swallowing dry food?

\section{Oral tests}

Unstimulated whole salivary flow $\leq 1.5 \mathrm{ml}$ in $15 \mathrm{~min}$

Parotid sialography shows diffuse sialectasis

Salivary scintigraphy shows delayed uptake of tracer

Salivary scintigraphy shows reduced concentration of tracer

Serology

Presence of either anti-Ro or anti-La antibodies

Notes: A category is considered positive when there is least one finding in the category. Sjögren's is diagnosed when there are positive findings in ocular signs, symptoms, and oral symptoms with either positive biopsy or evidence of antibodies on serology.

experience significantly fewer postoperative infections and complications than patients who suspend use. ${ }^{59}$

The final step in preoperative assessment is a thorough eye history and physical exam, as outlined in Table 5. History and physical findings that exclude a patient from consideration include any history of ocular involvement, secondary SS, an abnormal Schirmer or TBUT test, or slit-lamp evidence of dry eye, such as filaments or erosions. Postoperatively, patients should receive regularly scheduled follow-up for a minimum of 6 months.

\section{Systemic lupus erythematosus}

The studies above included 49 eyes of SLE patients, and reported results similar to the RA patients; most achieved

Table 5 Pre-LASIK eye evaluation for patients with collagen vascular disease

\begin{tabular}{l} 
Normal external structures \\
No lid involvement or lesions \\
Normal tear function \\
Evaluate tear film on slit lamp exam \\
Normal Schirmer test \\
Normal tear break up time test \\
Intact cornea with no epithelial defects \\
Check for filaments, erosive keratopathy \\
No signs of inflammation or uveitis \\
No evidence of retinopathy \\
Check for vascular abnormalities, microaneurysms, hemorrhage \\
No cotton wool spots or hard exudates \\
Fluorescein angiography for subtle lesions \\
\hline
\end{tabular}

good refractive outcomes without significant complications. While there are a few reports of significant postoperative corneal complications in SLE patients after cataract surgery, these patients all had either a documented history of active disease flare at the time of surgery or secondary SS. We therefore suggest patients with well-controlled SLE and no evidence of ocular complications or comorbid SS are suitable LASIK candidates if they can satisfy stringent preoperative selection criteria.

\section{Preoperative evaluation}

The patient's rheumatologist should evaluate disease activity as outlined in Table 6. Signs of lupus flares include systemic symptoms such as fever, fatigue, malaise, and characteristic skin-exam findings such as malar rash, photosensitive rash, or discoid lesions. Serologic evaluation is critical, as SLE flares

Table 6 Preoperative evaluation of SLE flare symptoms

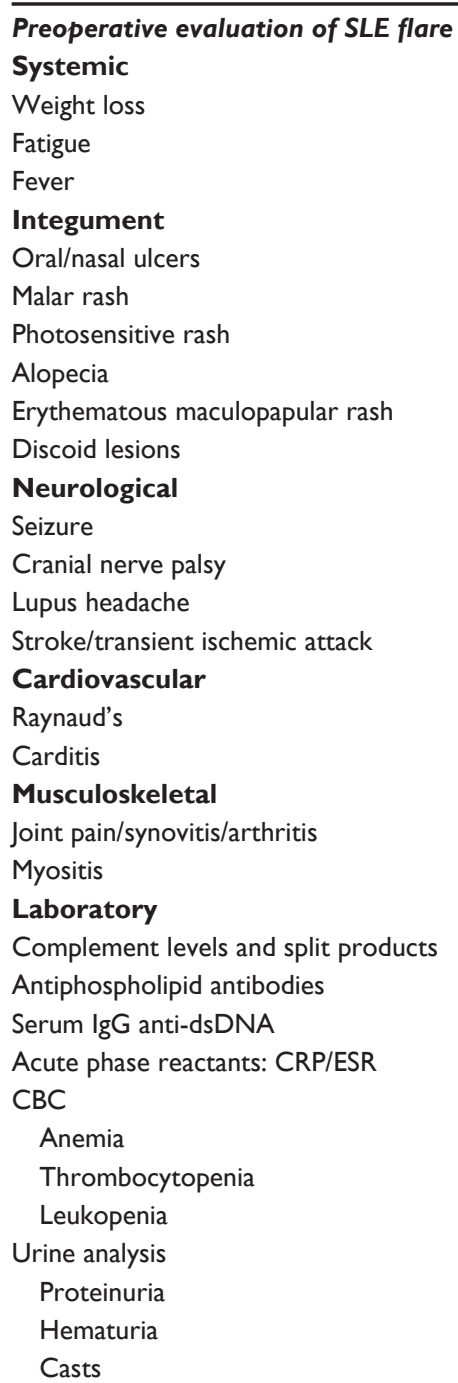

Abbreviations: $\mathrm{CBC}$, complete blood count; CRP, C-reactive protein; ESR, erythocyte sedimentation rate; SLE, systemic lupus erythematosus. 
are often preceded by a rise in serum immunoglobulin anti-dsDNA titers, a fall in serum complement levels, and an elevation of complement split products. ${ }^{60-65}$ Increased erythrocyte sedimentation rate and serum C-reactive protein concentrations are also reliable serologic indicators of disease activity, and seem to be particularly sensitive for eye and pulmonary involvement, and should therefore be evaluated as part of the preoperative evaluation. ${ }^{66}$ Suitable surgical candidates should be SLE symptom-free for at least 6 months, with no evidence of flare on physical exam and serology within normal limits. As with RA, we also recommend documented evidence of a negative SS workup (Table 4). The patient's medication regimen should be assessed using the same criteria applied to RA patients. Patients with multiple-drug regimens or on chronic corticosteroids should be excluded.

A complete eye history and exam should be performed using the same preoperative eye evaluation that applied to RA patients (Table 5). History and physical findings that exclude a patient from consideration include any history of eye involvement, such as lupus retinopathy, comorbid SS, an abnormal Schirmer or TBUT test, or evidence of dry eye on slit-lamp exam. Postoperatively, patients should receive regularly scheduled follow-up for a minimum of 6 months.

\section{Seronegative spondyloarthropathies}

The literature includes a total of 24 eyes of patients with documented SpA who received LASIK surgery. All of these eyes did well postoperatively, with unremarkable refractive outcomes and no reported complications. While Moshirfar et al reported a significant incidence of postoperative uveitis in their group of HLA-B27-positive patients, they found the incidence was no higher than the control population. Further, such a significant time period between surgery and uveitis flare (mean 13 months) made it unlikely that LASIK was the precipitating factor. ${ }^{50}$ These patients have also demonstrated good outcomes in the limited studies on other types of eye surgery. Further, the ocular manifestations of SpA are more acute and self-limiting than the complications associated with the other collagen vascular diseases. Many patients only experience one episode of uveitis, reflected by the low recurrence rate. We suggest that patients with SpA can safely receive LASIK surgery if they meet the preoperative selection criteria recommended below.

\section{Preoperative evaluation}

Patients should undergo a full rheumatology evaluation to determine the state of the disease. The rheumatic evaluation of SpA consists of an assessment of the patient's current symptoms, physical exam, laboratory testing, and imaging (Table 7). The patient's medication regimen should be evaluated according to that recommended for patients with RA and SLE. A full eye history and exam should be conducted (Table 5). Any patient with a history of recurrent uveitis should be excluded. We suggest that patients with a history of isolated uveitis may be considered for surgery, but we recommend the use of the same inclusion criteria applied by Moshirfar et al. Patients with a prior episode of uveitis should only be considered for LASIK after one full year has passed since their uveitis, and they should be evaluated and cleared by a uveitis specialist prior to surgery. ${ }^{50}$ Because comorbid SS is rare, a negative SS workup is not indicated in these patients unless they complain of suspicious symptoms, or signs of dry eye are present on exam.

\section{Sjögren's syndrome}

Patients with primary SS were poorly represented in the studies of LASIK in patients with CVD. This is likely because the strict inclusion criteria mandated normal tear function and no history of clinically significant dry eye, thus excluding almost every patient with either primary or secondary SS. Further, every reported case of moderate or severe postoperative complications after cataract surgery in CVD patients occurred in a patient with primary or secondary SS. Therefore, at this time we recommend against LASIK surgery in patients with SS, although more investigation into this issue is warranted.

Table 7 Preoperative evaluation of spondyloarthropathy

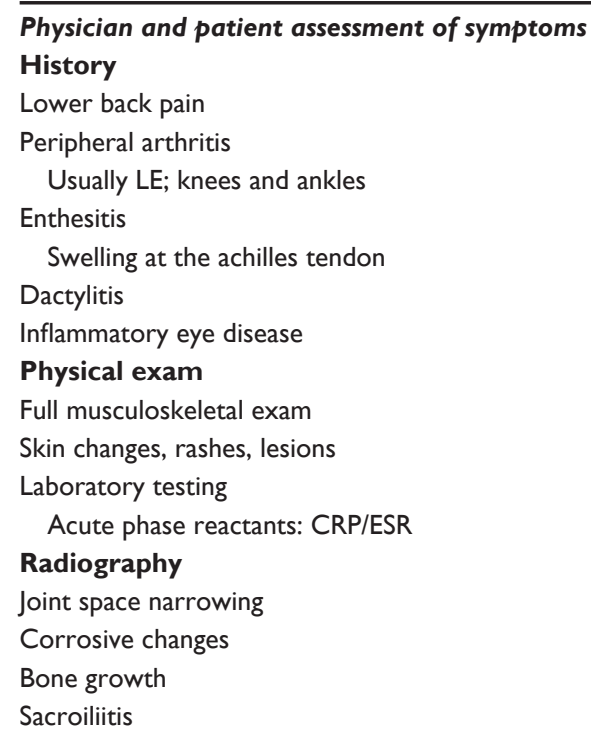

Abbreviations: LE, lower extremity; CRP, C-reactive protein; ESR, erythrocyte sedimentation rate. 


\section{Limitations}

The most significant limitation of this review is the overall lack of data available on this topic. There are no randomized, prospective studies that have examined this topic, and only four retrospective case studies. The sample size reflected in these four studies is small $(\mathrm{n}<200)$ and the individual conditions within the CVD spectrum all have an even smaller sample size $(\mathrm{n}<50)$. These sample sizes are not large enough to alter existing clinical guidelines. There are also significant flaws and bias associated with any type of retrospective case series, including accuracy of the medical records, selection bias, and lack of a control population, which is a flaw of many of the studies used in this review. Further, these retrospective studies all included slightly different subsets of diseases, one included "rheumatic" diseases, one focused on "autoimmune conditions," and a third was focused on "systemic illness." None was entirely specific to the four diseases considered in this review. While there was consistency in the patientinclusion criteria for all these studies, they all measured slightly different clinical outcomes, which makes interpretation of the data challenging. We recommend that additional investigation is needed on this topic to clarify precisely which patients make safe candidates for LASIK. Until that data is available, the recommendations provided are based on the reported outcomes from the existing studies on this topic, outcomes from other types of ocular surgery, and an understanding of the underlying ocular pathology associated with each condition.

\section{Conclusion}

Patients with CVD who desire LASIK surgery for elective vision correction represent a challenging treatment dilemma. Currently, the FDA and AAO consider CVD a relative contraindication to LASIK surgery, due to concerns that the comorbid ocular conditions may lead to poor refractive outcomes and significant postoperative complications. A review of the existing clinical data on this topic reveals that some patients with CVD may be suitable candidates for LASIK surgery, so long as their systemic disease is mild and they do not have a history of ocular complications. Based on these data, we propose that patients with RA, SLE, or SpA can achieve successful outcomes from LASIK surgery as long as the patient meets the stringent assessment criteria detailed above; however, we recommend against LASIK in any patient with symptomatic dry eye due to either primary or secondary SS due to an increased risk for postoperative complications. Further, we strongly encourage further investigation into this topic to better characterize the risks of LASIK in these patients and further clarify appropriate selection criteria.

\section{Disclosure}

Funding was received from the Research to Prevent Blindness Foundation (New York, NY) and the Semnani Family Foundation. The authors have no financial interests in any materials or products discussed in the manuscript or have any other financial disclosures.

\section{References}

1. Cobo-Soriano R, Beltrán J, Baviera J. LASIK outcomes in patients with underlying systemic contraindications. Ophthalmology. 2006;113(7): 1118.e1-1118.e8.

2. Smith RJ, Maloney RK. Laser in situ keratomileusis in patients with autoimmune diseases. J Cataract Refract Surg. 2006;32(8) 1292-1295.

3. United States Food and Drug Administration. Medical Devices: When Is LASIK Not for Me? Available from: http://www.fda.gov/ medicaldevices/productsandmedicalprocedures/surgeryandlifesupport/ lasik/ucm061366.htm. Accessed July 18, 2012.

4. Pillemer SR, Matteson EL, Jacobsson LT, et al. Incidence of physiciandiagnosed primary Sjögren syndrome in residents of Olmsted County, Minnesota. Mayo Clin Proc. 2001;76(6):593-599.

5. Ramos-Casals M, Tzioufas AG, Font J. Primary Sjögren's syndrome: new clinical and therapeutic concepts. Ann Rheum Dis. 2005;64(3): 347-354.

6. Fox RI. Sjögren's syndrome. Lancet. 2005;366(9482):321-331.

7. Fox RI, Michelson CA, Casiano J, Hayashi J, Stern M. Sjögren's syndrome. Clin Dermatol. 2000;18(5):589-600.

8. Garcia-Carrasco M, Fuentes-Alexandro S, Escárcega RO, Saldago G, Reibeling C, Cevera R. Pathophysiology of Sjogren's syndrome. Arch Med Research. 2006;37(8):921-932.

9. Xanthou G, Tapinos NI, Polihronis M, Nezis IP, Margaritis LH, Moutsopoulos HM. CD4 cytotoxic and dendritic cells in the immunopathologic lesion of Sjögren's syndrome. Clin Exp Immunol. 1999;118(1):154-163.

10. Borda E, Camusso JJ, Perez Leiros C, et al. Circulating autoantibodies against neonatal cardiac muscarinic acetylcholine receptor in patients with Sjögren's syndrome. Mol Cell Biochem. 1996;163-164(1):335-341.

11. Omerod LD, Fong LP, Foster CS. Corneal infection in mucosal scarring disorders and Sjögren's syndrome. Am J Ophthalmol. 1988;15(5): $512-518$.

12. Spector TD. Rheumatoid arthritis. Rheum Dis Clin North Am. 1990;16(3):513-537.

13. Thompson AU, Eadie S. Keratoconjunctivitis sicca and rheumatoid arthritis. Ann Rheum Dis. 1956;15(1):21-25.

14. Fuerst DJ, Tanzer DJ, Smith RE. Rheumatoid diseases. Int Ophthalmol Clin. 1998;38(4):47-80.

15. Harper SL, Foster CS. The ocular manifestations of rheumatoid disease. Int Ophthalmol Clin. 1998;38(1):1-19.

16. McGavin DD, Williamson J, Forrester JV, et al. Episcleritis and scleritis. A study of their clinical manifestations and association with rheumatoid arthritis. Br J Ophthalmol. 1976;60(3):192-226.

17. Huizinga TW, Grondal G. Shared symptoms in rheumatic diseases: a blessing or a curse? Arthritis Rheum. 2009;60(9):2547-2549.

18. Scott DG, Bacon PA, Tribe CR. Systemic rheumatoid vasculitis: a clinical and laboratory study of 50 cases. Medicine (Baltimore). 1981; 60(4):288-297.

19. Chakravarty EF, Bush TM, Manzi S, Clarke AE, Ward MM. Prevalence of adult systemic lupus erythematosus in California and Pennsylvania in 2000: estimates obtained using hospitalization data. Arthritis Rheum. 2007;56(6):2092-2094. 
20. Steinberg AD, Talal N. The coexistence of Sjögren's syndrome and systemic lupus erythematosus. Ann Intern Med. 1971;74(1):55-61.

21. Soo MP, Chow SK, Tan CT, Nadior N, et al. The spectrum of ocular involvement in patients with systemic lupus erythematosus without ocular symptoms. Lupus. 2000;9(7):511-514.

22. Jensen JL, Bergem HO, Gilboe IM, Husby G, Axell T. Oral and coular sicca symptoms and findings are prevalent in systemic lupus erythematosus. J Oral Pathol Med. 1999;28(7):317-322.

23. Sivaraj RR, Durrani OM, Denniston AK, Murray PI, Gordon C. Ocular manifestations of systemic lupus erythematosus. Rheumatology. 2007;46(12):1757-1762.

24. Stafford-Brady FJ, Urowitz MB, Gladman DD, Easterbrook M. Lupus retinopathy: patterns, associations, and prognosis. Arthritis Rheum. 1988;31(9):1105-1110.

25. Gold DH, Morris DA, Henkind P. Ocular findings in systemic lupus erythematosus. Br J Ophthalmol. 1972;56(11):800-804.

26. Arevalo JF, Lowder CY, Muci-Mendoza R. Ocular manifestations of systemic lupus erythematosus. Curr Opin Ophthalmol. 2002;13(6): 404-410.

27. Shern MA, Pirofsky B. Disseminated lupus erythematosus: analysis of thirty-four cases. Arch Intern Med. 1952;90(6):790-807.

28. Lanham JG, Barrie T, Kohner EM, et al. SLE retinopathy: evaluation of fluorescein angiography. Ann Rhuem Dis. 1982;41(5):473-478.

29. Nguyen QD, Foster CS. Systemic lupus erythematosus and the eye. Int Ophthalmol Clin. 1998;38(1):33-60.

30. Hahn BH, Karpouza GA, Tsao BP. Pathogenesis of systemic lupus erythematosus. In: Harris E, Budd R, Genovese M, Firestein G, Sargent J, Sledge C, editors. Kelley's Textbook of Rheumatology. 7th ed. Philadelphia: WB Saunders; 2005:1174-1200.

31. Karpik AG, Schwartz MM, Dickey LE, Streeten BW, Roberts JL. Ocular immune reactants in patients dying with systemic lupus erythematosus. Clin Immunol Immunopathol. 1985;35(3):295-312.

32. Fox RI, Liu AY. Sjögren's syndrome in dermatology. Clin Dermatol. 2006;24(5):393-413.

33. Reveille JD, Hirsch R, Dillon CF, Carroll MD, Weisman MH. The prevalence of HLA-B27 in the United States: data from the US National Health and Nutrition Examination Survey, 2009. Arthritis Rheum. 2012;64(5):1407-1411.

34. Hannu T. Reactive arthritis. Best Pract Res Clin Rheumatol. 2011; 25(3):347-357.

35. Zeboulon N, Dougados M, Gossec L. Prevalence and characteristics of uveitis in the spondyloarthropathies: a systematic literature review. Ann Rheum Dis. 2008;67(7):955-959.

36. Khan MA. Update on spondyloarthropathies. Ann Internal Med. 2002;136(12):896-907.

37. Salvarani C, Olivieri I, Cantini F, Macchioni L, Boiardi L. Psoriatic arthritis. Curr Opin Rheumatol. 1998;10(4):299-305.

38. Rosenbaum JT. Acute anterior uveitis and spondyloarthropathies. Rheum Dis Clin North Am. 1992;18(1):143-151.

39. Martin TM, Smith JR, Rosenbaum JT. Anterior uveitis: current concepts of pathogenesis and interactions with the spondyloarthropathies. Curr Opin Rheumatol. 2002;14(4):337-341.

40. Matsuo T, Fujiwara M, Matsuo N. Inflammation after cataract extraction and intraocular lens implantation in patients with rheumatoid arthritis. Br J Ophthalmol. 1995;79(6):549-553.

41. Jones RR, Maguire LJ. Corneal complications after cataract surgery in patients with rheumatoid arthritis. Cornea. 1992;11(2):148-150.

42. Fox GM, Flynn HW Jr, Davis JL, Culbertson W. Causes of reduced visual acuity on long-term follow-up after cataract extraction in patients with uveitis and juvenile rheumatoid arthritis. Am J Ophthalmol. 1992;114(6):708-714.

43. Maffett MJ, Johns KJ, Parrish CM, et al. Sterile corneal ulceration after cataract extraction in patients with collagen vascular disease. Cornea. 1990;9(4):279-285.

44. Seiler T, Wollensak J. Complications of laser keratomileusis with the excimer laser (193 nm) [German]. Klin Monatsbl Augenheilkd. 1992; 200(6):642-653
45. Shannon JC, Shan MS, Wu EI, Akpek EK. Sterile corneal melt after Descemet stripping endothelial keratoplasty in patients with previously undiagnosed Sjögren syndrome. Arch Ophthalmol. 2009;127(2): 219-221.

46. Ou JI, Manche EE. Corneal perforation after conductive keratoplasty in a patient with previously undiagnosed Sjögren syndrome. Arch Ophthalmol. 2007;125(8):1131-1132.

47. Papaconstantinou D, Georgopoulos G, Kalantzis G, Krassas A, Georgalas I. Peripheral ulcerative keratitis after trabeculectomy in a patient with rheumatoid arthritis. Cornea. 2009;28(1):111-113.

48. Perez VL, Azar DT, Foster CS. Sterile corneal melting and necrotizing scleritis after cataract surgery in patients with rheumatoid arthritis and collagen vascular disease. Semin Ophthalmol. 2002;17(3-4): 124-130.

49. Alió JL, Perez-Santonja JJ, Rodriguez-Prats J. LASIK in patients with rheumatic diseases: a pilot study. Ophthalmology. 2005;12(11): 1948-1954.

50. Moshirfar M, Siddharthan KS, Meyer JJ, Espandar L, Wolsey DH, Vitale AT. Uveitis after laser in situ keratomileusis in patients positive for human leukocyte antigen-B27. J Cataract Refract Surg. 2008; 34(7):1110-1113.

51. Li Y, Li HY. Analysis of clinical characteristics and risk factors of corneal melting after laser in situ keratomileusis [Chinese]. Zhonghua Yan Ke Za Zhi. 2005;41(4):330-334.

52. Lahners WJ, Hardten DR, Lindstrom RL. Peripheral keratitis following laser in situ keratomileusis. J Refract Surg. 2003;19(6):671-675.

53. Liang L, Zhang M, Zou W, Liu Z. Aggravated dry eye after laser in situ keratomileusis in patients with Sjögren syndrome. Cornea. 2008;27(1): 120-123.

54. Diaz-Valle D. Late-onset severe diffuse lamellar keratitis associated with uveitis after LASIK in a patient with ankylosing spondylitis. J Refract Surg. 1995;25(7):623-625.

55. Saag KG, Teng GG, Patkar NM, et al. American College of Rheumatology 2008 recommendations for the use of nonbiologic and biologic disease-modifying antirheumatic drugs in rheumatoid arthritis. Arthritis Rheum. 2008;59(6):762-784.

56. American College of Rheumatology Subcommittee on Rheumatoid Arthritis Guidelines. Guidelines for the management of rheumatoid arthritis: 2002 update. Arthritis Rheum. 2002;46(2):328-346.

57. Khanna D, Ranganath VK, Fitzgerald J, et al. Increased radiographic damage scores at the onset of seropositive rheumatoid arthritis in older patients are associated with osteoarthritis of the hands, but not with more rapid progression of damage. Arthritis Rheum. 2005;52(8): 2284-2292.

58. Nishimura K, Sugiyama D, Kogata Y, Tsuji G, Nakazawa T, Kawano S. Meta-analysis: diagnostic accuracy of anti-cyclic citrullinated peptide antibody and rheumatoid factor for rheumatoid arthritis. Ann Intern Med. 2007;146(11):797-818.

59. Grennan DM, Gray J, Loudon J, Fear S. Methotrexate and early postoperative complications in patients with rheumatoid arthritis undergoing elective orthopaedic surgery. Ann Rheum Dis. 2001;60(3): 214-217.

60. Bootsma H, Spronk PE, Ter Borg EJ, Hummel EJ, de Boer G, Limburg PC. The predictive value of fluctuations in IgM and IgG class anti-dsDNA antibodies for relapses in systemic lupus erythematosus. A prospective long-term observation. Ann Rheum Dis. 1997;56(11): 661-666.

61. Lloyd W, Schur PH. Immune complexes, complement, and anti-DNA in exacerbations of systemic lupus erythematosus (SLE). Medicine (Baltimore). 1981;60(3):208-217.

62. Ho A, Magder LS, Barr SG, Petri M. Decreases in anti-double-stranded DNA levels are associated with concurrent flares in patients with systemic lupus erythematosus. Arthritis Rheum. 2001;44(10):2342-2349.

63. Linnik MD, Hu JZ, Heilbrunn KR, et al. Relationship between antidouble-stranded DNA antibodies and exacerbation of renal disease in patients with systemic lupus erythematosus. Arthritis Rheum. 2005; 52(4):1129-1137. 
64. Kao AH, Navratil JS, Ruffing MJ, et al. Erythrocyte C3d and C4d for monitoring disease activity in systemic lupus erythematosus. Arthritis Rheum. 2010;62(3):837-844.

65. Ho A, Barr SG, Magder LS, Petri M. A decrease in complement is associated with increased renal and hematologic activity in patients with systemic lupus erythematosus. Arthritis Rheum. 2001;44(10): 2350-2357.
66. Bertoli AM, Vilá LM, Reveille JD, Alarcón GS; LUMINA Study Group. Systemic lupus erythematosus in a multiethnic US cohort (LUMINA): LXI. Value of C-reactive protein as a marker of disease activity and damage. J Rheumatol. 2008;35(12):2355-2358.

\section{Publish your work in this journal}

Clinical Ophthalmology is an international, peer-reviewed journal covering all subspecialties within ophthalmology. Key topics include: Optometry; Visual science; Pharmacology and drug therapy in eye diseases; Basic Sciences; Primary and Secondary eye care; Patien Safety and Quality of Care Improvements. This journal is indexed on

Submit your manuscript here: http://www.dovepress.com/clinical-ophthalmology-journal

\section{Dovepress}

PubMed Central and CAS, and is the official journal of The Society of Clinical Ophthalmology (SCO). The manuscript management system is completely online and includes a very quick and fair peer-review system, which is all easy to use. Visit http://www.dovepress.com/ testimonials.php to read real quotes from published authors. 